\title{
Design of Mobile Learning System for English Grammar
}

\author{
Liu Dan \\ Bohai University, Jinzhou, P.R. China \\ myld81@163.com
}

Keywords: English grammar; mobile learning; demand analysis; summary design; design of system process

\begin{abstract}
Today, English has become the highest penetration rate of foreign languages in our country. Mastering and using English grammar is critical to learn English well. In order to improve the students' interest in learning English grammar and efficiency and the standard of English in a short time, in this paper, designed on mobile learning system of English grammar, lay the foundation for subsequent software development. The system mainly carries on the demand analysis, summary design and the design of system process. Among them, Needs analysis using the data flow graph analysis functions of the system to be completed; Summary design by using the structure diagram designs all the function of the system; The design of system process by using the flow chart designs procedure of complete system. The research contents of this thesis have important significance for promoting the study of English grammar, a short period of time to improve students' English level etc.
\end{abstract}

\section{Introduction}

English grammar is the specification of the English language itself, is a summary and description of language phenomenon [1]. In the learning process, Although students can remember many of the rules, But it is not used in the proper places, The result is a learned so dead, listening, speaking, reading and writing skills do not increase, and will feel boring English class [2]. Teachers in the learning process, blindly reference books to instill in students a lot of grammar, students passively accept, in the end, learned a lot of knowledge of grammar, but still don't understand, could not speak, write not well [3]. With the development of intelligent mobile phone, mobile learning has become more and more widely, how to use the mobile phone to realize intelligent mobile learning English grammar, this is a topic worthy of study. It will be a lot of idle time to good use, thus prolonging the students of English grammar learning time to a great extent, improve the efficiency and effectiveness of learning English grammar [4]. In order to improve the students' interest in learning English grammar and efficiency and the standard of English in a short time, in this paper, designed on mobile learning system of English grammar, lay the foundation for subsequent software development.

\section{Demand Analysis}

The so-called "Demand analysis", refers to the detailed analysis of the problem to be solved, find out problems' requirements, including what you need to input data, to get what, what should the final output. It can be said that, in the software engineering "Demand analysis" is sure to computer "what to do", to achieve what effect. It can be said that the demand analysis is done before the system will do [5].

Demand analysis is usually a data flow diagram to describe the system logic model. According to the hierarchy of data flow diagram is divided into a top level data flow diagram, a middle level data flow diagram and a bottom level data flow diagram. This paper designed the system of top level data flow diagram, as shown in Fig. 1.

In Fig. 1, there are three entities, namely: "students", "teachers" and "administrator". Among them, "students" send "login" request to system, After the success, the system will give "feature selection" feedback to "students", "students" can choose the required functions; "administrator" 
sends "information release", the system will send the latest information to "teachers" and "students", at the same time, "administrator" through system obtain the data of "teachers" and "students" can do "data statistics"; "teachers" send "Business management" request to system, after the success , the selected system business information feedback "information display" to "teachers", "teachers" can make the appropriate business management.

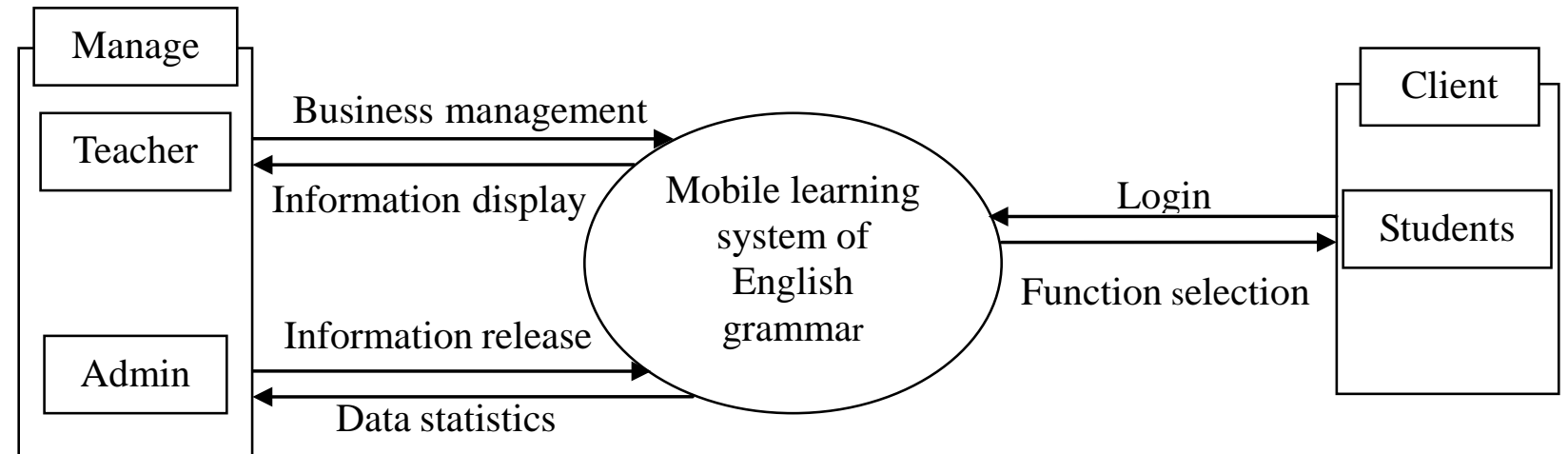

Fig. 1. System of top level data flow diagram

\section{Summary Design}

Summary design is the next step to be analyzed, the main task is to get the DFD needs analysis converting software architecture [6]. Summary design usually use configuration diagram to depict a functional configuration of the software, a structure diagram of the system shown in Fig. 2.

In Fig. 2, the name of the top level with a system of "mobile learning English grammar system" said. The second layer is divided into "student", "teacher" and "Administrator" three kinds of users, each represents a module. The third layer with specific functions, where "students" user functions include online learning, online tests, online counseling, registered accounts, change passwords, check teachers information; "teachers" user functions include online lectures, online answers, online marking, manage students information; "administrator" user functions include account management, information updates, question bank management, system maintenance.

In each module, the definition of each specific function has its specific meaning. For example, in "teachers" module, online marking says teachers online mark students' questions after test; in "administrator" module, question bank management says administrator makes unified management of students' test questions and learning materials.

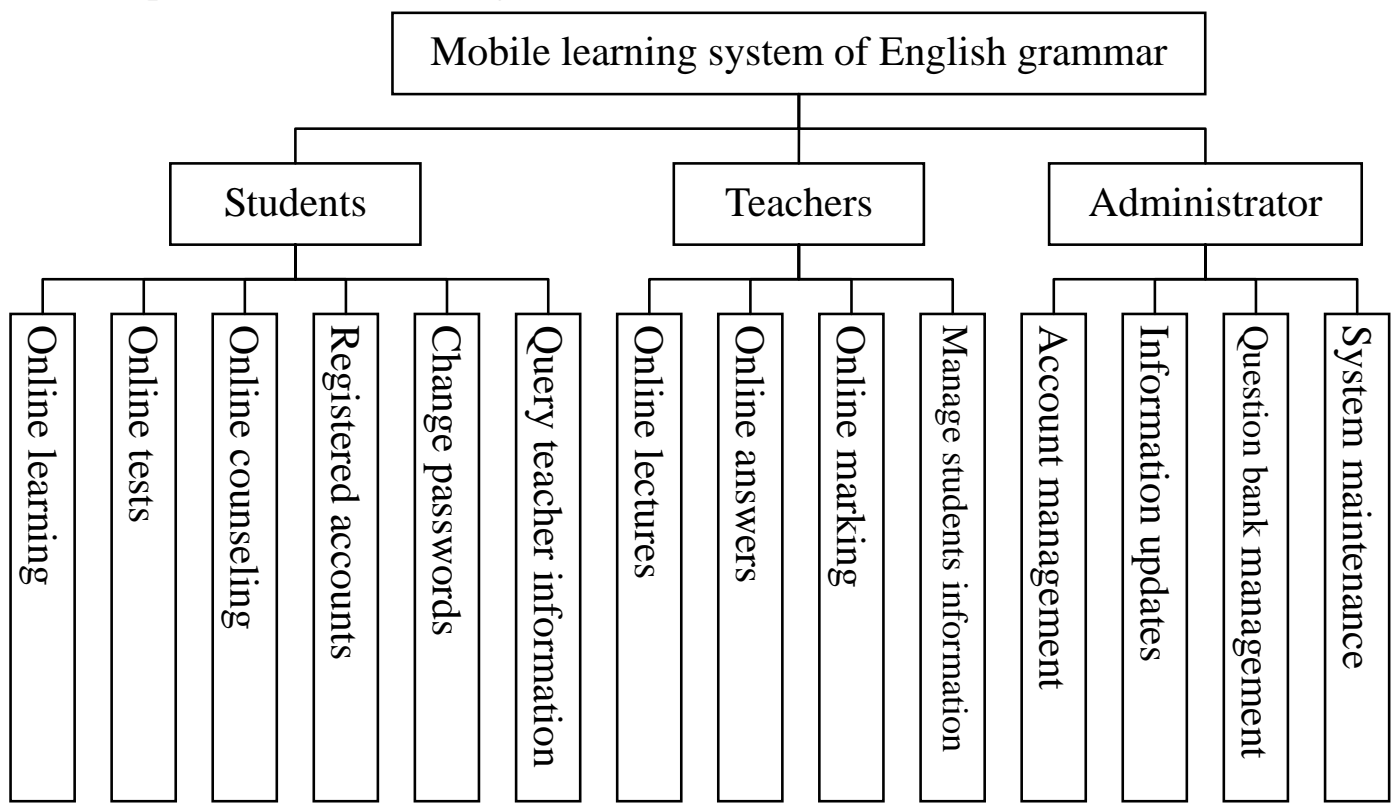

Fig. 2. Functional design of mobile learning system of English grammar 


\section{Design of System Process}

The system process can be depicted by flow chart of the system. The flow chart of the system is the traditional tools of drawing system physical model, expressing the flow of components of the system, rather than the control process of information processing [7]. The system is divided into students, teachers, administrators of three users, the user to students as an example to illustrate the process of the design of system process, as shown in Fig. 3.

System Process Design Description: After the user starts the application, enter the login screen, when a user logs on to the system, the system prompts the user whether the account; if there is, the user is prompted to enter a user name and password; if not, the user is prompted to register account, after successful registration, re entering the login interface, input the registered user name and password. If the input is correct, enter the main interface, the user can select function, performs the required operation; otherwise, enter again, until you enter the correct user name and password, may also exit the system. When the user finishes execution of all operations, withdraw from the system, the end.

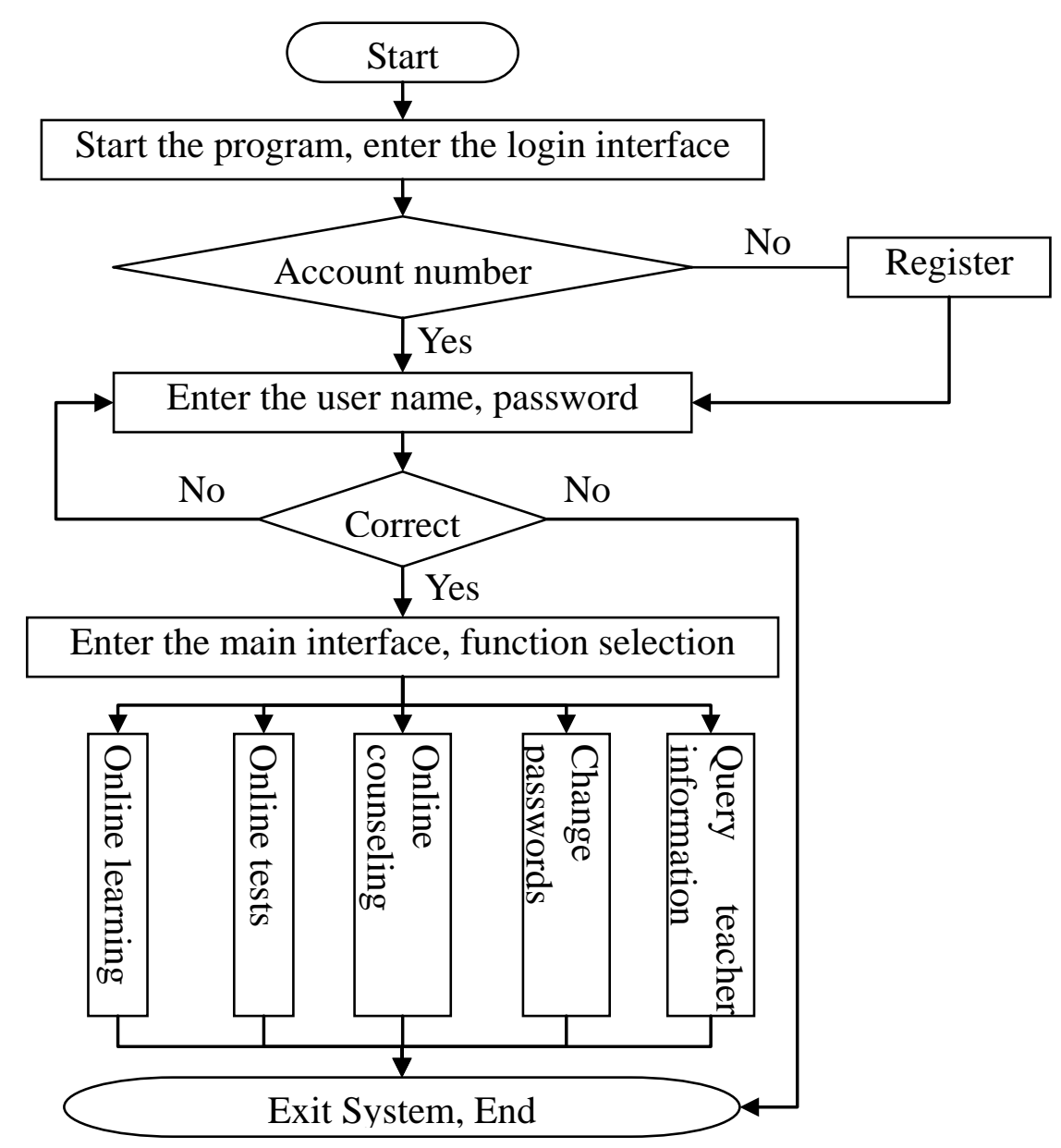

Fig. 3. The student user flow chart

\section{Future Development of Mobile Learning}

Our country in the next two decades, the development of mobile learning will go through three stages: basic environmental construction phase, the knowledge system construction phase and learning services construction phase, the transition between each stage is the process of iteration.

The first stage is the basis for environmental construction phase, will be with the development of the wireless network and resource gradually formed foundation environment to adapt to the mobile learning, and gradually form a national, regional and three levels of the organization of the network application environment and Thematic Resources learning environment; 
The second stage is the stage of building the knowledge system, will build a large-scale knowledge system based on the existing sound mobile environment, make learning content internalize association and compatible with existing resources sharing, classify according to different learning subject and the demand and build customized applications;

The third stage is the learning services construction stage, this stage will be a new starting point for the process of Comprehensive education socialization development in our country, environment interactions become recessive mobile learning process, the national service center of mobile learning becomes a social infrastructure, mobile learning becomes social education form, the related resources systematically carry on the merger and integration [8].

\section{Conclusion}

Mobile learning is a new research field, it is through the effective combination of mobile computing technology based on digital learning, can help learners acquire the knowledge they want information at any time and place, to realize the true meaning of autonomous learning, and eventually realize the learning socialization, lifelong [9]. Learning English grammar in the past are using traditional methods, students can only learn through books and in class listening, which not only limits the ability of independent study for the students, but also reduce the interest and efficiency of students in learning English grammar. With the development and popularization of mobile terminal, network technology, network learning in the mobile terminal as the core has become a popular way of current study. At present, the mobile terminal technology has become increasingly mature, stable, wide coverage, but only applied to public information sharing, network, information interaction and other fields, rarely in learning grammar application. Mobile learning system of English grammar based on this paper, can make full use of mobile terminal technology to improve the students' interest and efficiency of learning grammar of, it has important significance for promoting the study of English grammar, a short period of time to improve students' English level etc.

\section{References}

[1] X. Li, "Exploration of the reform of English Grammar Teaching," Education for Chinese After-school (Theory), vol. 3, no. S3, pp. 132, 2009.

[2] G. X. Zhu, "On learning of English grammar," Journal of The Second Northwest University for Nationalities (Philosophy and Social Science), vol. 49, no. 2, pp. 86-87, 2001.

[3] X. Y. Zhou, "On learning of English grammar," Journal of Higher Correspondence Education (Natural Sciences), vol. 19, no. S1, pp. 100-102, 2006.

[4] Y. Ruan, Y. L. Ma, "Intelligent mobile phone environment English mobile learning system design and Implementation," Electronic Test, no. 9, pp. 13-15, 2014.

[5] Baidu Encyclopedia, "Demand analysis," http://baike.baidu.com/view/111493.htm, 2014-09-29.

[6] Baidu Encyclopedia, "Summary Design," http://baike.baidu.com/view/551728.htm?fr=aladdin, 2014-09-29.

[7] Baidu Encyclopedia, "Flow Chart," http://baike.baidu.com/view/1140574.htm?fr=aladdin, 2014-09-29.

[8] Baidu Encyclopedia, "Mobile Learning," http://baike.baidu.com/view/3003454.htm?fr=aladdin, 2014-09-29.

[9] L. Y. Wang, H. Wu, L. Y. Wang, "Design and Realization of English Grammar Mobile Learning System Based on Android," Computer and Modernization, vol. 216, no. 8, pp. 232-235, 2013. 